\title{
HUBUNGAN SELF CARE DENGAN KOMPLIKASI DIABETES MELITUS PADA PASIEN DENGAN DIABETES MELITUS TIPE 2 DI KLINIK HUSADA SARIO MANADO
}

\author{
Antania Sasombo $^{a^{*}}$, Mario Esau Katuuk ${ }^{\mathbf{b}}$, Hendro Bidjuni ${ }^{\mathrm{c}}$ \\ aMahasiswa Program Studi Ilmu Keperawatan Fakultas Kedokteran Universitas Sam \\ Ratulangi \\ ${ }^{b}$ Dosen Program Studi Ilmu Keperawatan Fakultas Kedokteran Universitas Sam Ratulangi \\ 'Dosen Program Studi Ilmu Keperawatan Fakultas Kedokteran Universitas Sam Ratulangi
}

Email: antaniasasombo1996@gmail.com

\begin{abstract}
Background: diabetes mellitus is a metabolic disease characterized by hypoglycemia. Diabetes effects can result in the body's organs if the condition is not managed or controlled properly. For this reason, it is necessary to do DM self-care which is an independent action that must be taken by DM Sufferers in their daily lives to control Blood Glucose. Aim: This study was aimed to determine corelation between the self-care whit the complications of patients with type 2 diabetes mellitus at the Husada Sario Manado Clinic. Methods:This research is a corrosive cross-sectional study, it's done to 72 patients with type 2 Diabetes Melitus with research tools from questionnaire and analysis using chi-square. Results: This research is picking up p-value results. Conclusion: Most of the Diabetes Melitus type 2 at he Husada Sario Manado Clinic has a good self care, with most of the patients having hypertensive complications. There's no link between self care and the complications of Diabetes Melitus on patients with type 2 Diabetes Melitus.
\end{abstract}

Keywords: Diabetes Mellitus type 2, complications of Diabetes Mellitus, Self Care.

Absrak
Latar belakang: Diabetes Melitus merupakan penyakit metabolik dengan karakteristik hipeglikemia. Jika diabetes tidak segera dikendalikan atau dikendalikan dengan baik dapat mengakibatkan komplikasi diabetes yang dapat terjadi pada organ-organ tubuh. Untuk itu perlu dilakukannya Self care DM yang merupakan tindakan mandiri yang harus dilakukan oleh penderita DM dalam kehidupanya sehari-hari untuk mengontrol glukosa darah.Tujuan penelitian untuk menganalisis hubungan self care dengan komplikasi Diabetes Melitus tipe 2 di Klinik Husada Sario Manado. Metode Penelitian ini adalah penelitian cross-sectional yang bersifat deskriptif korelatif, yang dilakukan kepada 72 pasien Diabetes Melitus tipe 2 dengan Instrument penelitian yang digunakan yaitu kuesioner dan dianalisis menggunakan Chi Square. Hasil Penelitian di dapati hasil p-value $(0,802)>\alpha=(0,05)$. Simpulan Sebagian besar pasien Diabetes Melitus tipe 2 di Klinik Husada Sario Manado memiliki self care baik, dengan sebagian besar pasien memiliki komplikasi hipertensi. Tidak ada hubungan yang signifikan antara Self Care dengan komplikasi Diabetes Melitus pada pasien dengan Diabetes Melitus tipe 2.

Kata Kunci : Diabetes Melitus tipe 2, komplikasi Diabetes Melitus, Self Care. 


\section{PENDAHULUAN}

Diabetes Melitus (DM) merupakan kategori penyakit tidak menular yang menjadi masalah kesehatan masyarakat, baik secara global maupun lokal.Penyakit ini terus mengalami peningkatan dari tahun ke tahun khususnya di negara - negara berkembang. Berdasarkan data dari International Diabetes Federation, prevalensi penyandang Diabetes Melitus (DM) tahun 2019 adalah sebanyak 463 juta jiwa di seluruh dunia dan diprediksi akan terus meningkat mencapai 700 juta jiwa pada tahun 2045 (IDF, 2019).

Data World Health Organization/ WHO (2013) menunjukkan bahwa sebanyak $80 \%$ penyandang DM di dunia berasal dari negara berkembang salah satunya adalah Indonesia. Indonesia masuk dalam 10 negara terbesar penderita DM di dunia dan menempati urutan ke- 6 dengan jumlah penyandang sebanyak 10,7 juta jiwa tahun 2019 (IDF, 2019). Jumlah penyandang DM terus mengalami peningkatan, hal ini berkaitan dengan jumlah penduduk yang meningkat, pola hidup yang berubah dari tradisional ke pola hidup modern, prevalensi obesitas meningkat, dan kegiatan fisik kurang.

Tingginya angka prevalensi Diabetes Melitus secara tidak langsung juga akan meningkatkan komplikasi yang diakibatkan oleh penyakit tersebut dan akan semakin tinggi jika pasien tersebut tidak memiliki usaha untuk merawat diri sendiri dengan baik. Menurut Brunner \& Suddarth (2002), penderita DM memiliki 2 komplikasi yaitu komplikasi akut dan komplikasi kronis. Komplikasi akut terdiri atas hipoglikemi, diabetes ketoasidosis dan hiperglikemi hiperosmolar nonketotik (HHNK). Untuk komplikasi akut diantaranya meliputi perubahan tingkat kesadaran, bicara pelo, penglihatan kabur, sakit kepala, peningkatan bedenyut nadi, dan ketika lambat menangani komplikasi dapat mengakibatkan kematian. Sedangkan komplikasi kronis dapat menyerang pembuluh darah yang menyebabkan stroke, atau infark miokard, ginjal, perdarahan pada retina, syaraf, kulit sampai pada amputasi (Brunner \& Suddarth, 2002). Berdasarkan data Riskesdas (2013), komplikasi terbanyak akibat DM di Indonesia adalah 545 dari seluruh penderita DM di Indonesia. Berdasarkan data yang sudah diuraikan oleh peneliti dan belum adanya penelitian tentang ini di daerah Manado, dan berdasarkan laporan Dinas Kesehatan SULUT (2016), terdapat 5652 kasus DM di tahun 2016, dengan prevalensi DM terbanyak yaitu kota manado sebanyak 3494 jiwa.

Peningkatan prevalensi DM yang terjadi secara signifikan, membutuhkan pengawasan dan pemantauan dalam penatalaksanaan DM dengan baik dan benar (Depkes RI, 2008). Jika tidak ditangani dengan baik dan benar, maka komplikasi yang terjadi akan lebih serius bahkan komplikasi yang terjadi akan semakin bertambah. Namun pasien seringkali tidak sanggup dalam melakukan perawatan diri, seperti menjalankan pengobatan secara mandiri, merawat kaki, mengatur pola makannya dan pemantauan kadar gula darah, sehingga tidak dapat mencegah munculnya komplikasi dan tidak dapat melakukan aktivitas sehari-hari dengan normal (Kurniawati, 2011). Self care memiliki hubungan yang erat yang dapat mempengaruhi kualitas hidup para pasien DM. Untuk itu perawatan diri (Self Care) sangat penting untuk pencegahan komplikasi pada DM (Chaidir, 2017).

Menurut Sigurdardottir (2005); Xu Yin et all (2008); dan didalam The Summary of Diabetes Self-Care Activities (SDSCA) oleh Toobert, D.J et all (2009), self care yang dilakukan pada pasien diabetes melitus meliputi pengaturan pola makan (diet), pemantauan kadar gula darah, terapi obat, perawatan kaki, dan latihan fisik (olah raga). Beberapa penelitian yang dilakukan, salah satunya menurut Sulistria, 2013 mengatakan dalam jurnalnya bahwa tingkat self ciare pada pasien ini belum sepenuhnya dilakukan. Aktivitas fisik dan pola makan sesudah baik, tetapi aktivitas perawatan kaki dan pengontrolan gula darah self care 
pasien masih rendah.Menurut penelitian Dewi (2012), mengatakan bahwa tingkat self care pada pasien DM masih sangat kurang karena beberapa faktor yang juga mempengaruhi pasien sehingga muncul komplikasi.

Penelitian yang di lakukan oleh kiranawati 2012 mengenai Hubungan Perilaku Perawatan Mandiri (Self Care Inventory) Dengan Jumlah Komplikasi Pada Penderita Diabetes Melitus Di Kelurahan Sumbersari Wilayah Kerja Puskesmas Dinoyo, didapatkan hasil bahwa ada hubungan antara perilaku perawatan mandiri (self care inventory).

Berdasarkan latar belakang tersebut penelitian ini bertujuan untuk menganalisis Hubungan self care dengan komplikasi Diabetes Melitus pada pasien dengan Diabetes Melitus tipe 2 di Klinik Husada Sario Manado.

\section{METODE}

Penelitian ini yaitu penelitian kuantitatif yang bersifat deskriptif korelasi yaitu penellitian hubungan antara dua variabel pada satu atau sekelompok subjek (Notoadmojo, 2012).

Sampel yang di ambil dalam penelitian ini ini yaitu sebanyak 72 pasien dengan menggunakan rumus proporsi analitik penarikan sampel estimasi proporsi dengan mengambil proporsi terhadap salah satu variabel yang akan diteliti yaitu Komplikasi Diabetes Melitus $(\mathrm{p}=0.05 \%)$. Kriteria inklusi pada penelitian ini yaitu pasien yang terdiagmos DM Tipe 2, dan pasien DM Tipe 2 yang aktif mengikuti program di Klinik.

Instrument penelitian menggunakan kuesione dan lembar observasi. Instrumen dalam pengumpulan data yaitu menggunakan kuesioner The Summery of Diabetes Self-Care Activities (SDSCA) yang sudah dimodifikasi dan di uji validasi dan reabilitasi dengan hasil tidak terdapat pertanyaan yang tidak valid.yang teridiri dari bagian A, yaitu data demografi (Umur, jenis kelamin, pendidikan, pekerjaann, ratarata pendapatan perbulan, lamanya menderita DM, komplikasi, merokok) dan bagian $\mathrm{B}$, yaitu pertanyaan - pertanyaan untuk menilai aktivitas self care pada pasien DM tipe 2. Kuesioner ini terdiri atas 17 pertanyaan yang meliputi pengaturan pola makan (diet) sebanyak 6 item pertanyaan, latihan fisik (olahraga) 2 item pertanyaan. Perawatan kaki 5 item pertanyaan, minum obat 2 item pertanyaan, dan monitoring gula darah sebanyak 2 item pertanyaan.

Jenis sumber data riwayat komplikasi pasien DM terbagi menjadi 2 bagian yaitu Data Primer yaitu data yang di peroleh langsung dari pasien Diabetes Melititus menggunakan lembar observasi dan data Sekunder. Data yang diperoleh dari dokumen-dokumen seperti buku, catatancatatan terkait yang sifatnya tertulis yang dapat menunjang proses penelitian yang diperoleh dari bagian yang terkait dengan peneliti.

Pengolahan data menggunakan uji Chisquare. Penelitian ini telah dilakukan dengan standar penelitian yang ada yaitu, memberikkan penjelasan kepada responden, meminta persetujuan, kerahasiaan informasi identitas dan kerahasiaan responden. Penelitian ini telah mendapat izin dari pihak Klinik untuk dijadikan tempat penelitian. 
Jurnal Keperawatan, Volume 9, No. 2, Agustus 2021, (Hal. 54-62)

\section{HASIL}

Tabel 1. Kategori Demografi Usia, Jenis Kelamin, Pendidikan, Pekerjaan, Rata-rata Pendapatan Perbulan, Lamanya Menderita Diabetes Melitus (DM), Komplikasi, dan Merokok $(\mathrm{N}=72)$

\begin{tabular}{|c|c|c|}
\hline Kategori & Frekuensi & $\%$ \\
\hline \multicolumn{3}{|l|}{ Usia } \\
\hline $26-35$ tahun & 0 & 0 \\
\hline $36-45$ tahun & 2 & 2.8 \\
\hline & 6 & 8.3 \\
\hline 46 - 55 tahun & 25 & 34.7 \\
\hline $\begin{array}{l}56-65 \text { tahun } \\
65 \text { tahun - ke atas }\end{array}$ & 39 & 54.2 \\
\hline \multicolumn{3}{|l|}{ Jenis kelamin } \\
\hline Laki - laki & 25 & 34.7 \\
\hline Perempuan & 47 & 65.3 \\
\hline \multicolumn{3}{|l|}{ Pendidikan } \\
\hline Tidak tamat SD & 2 & 2.8 \\
\hline Tamat SD & 2 & 2.8 \\
\hline SLTP/Sederajat & 7 & 9.7 \\
\hline SLTA/Sederajat & 31 & 43.1 \\
\hline Akademi/PT & 30 & 41.7 \\
\hline Lain - lain & 0 & 0 \\
\hline \multicolumn{3}{|l|}{ Pekerjaan } \\
\hline Tidak bekerja & 0 & 0 \\
\hline Buruh & 0 & 0 \\
\hline Petani & 0 & 0 \\
\hline Wiraswasta/pedagang & 19 & 26.4 \\
\hline PNS & 6 & 8.3 \\
\hline TNI/POLRI & 0 & 0 \\
\hline Lainya & 47 & 65.3 \\
\hline \multicolumn{3}{|l|}{$\begin{array}{l}\text { Rata - rata pendapatan perbualan } \\
\leq 1.900 .000,-\end{array}$} \\
\hline$\geq 1.900 .000$ & 15 & 20.8 \\
\hline & 57 & 79.2 \\
\hline \multicolumn{3}{|l|}{ Lamaya menderita DM } \\
\hline $3-12$ bulan & 2 & 2.8 \\
\hline $1-5$ tahun & 16 & 72.2 \\
\hline$>5$ tahun & 54 & 75.0 \\
\hline \multicolumn{3}{|l|}{ Komplikasi } \\
\hline Tidak mengalami komplikasi & 24 & 34.7 \\
\hline Mengalami komplikasi & 48 & 65.3 \\
\hline Gagal Ginjal & 1 & 1.4 \\
\hline Stroke & 2 & 2.8 \\
\hline Penyakit Jantung & 11 & 15.3 \\
\hline Hipertensi & 34 & 47.2 \\
\hline
\end{tabular}

Sumber : Data Primer, 2020

Berdasarkan table 1 diatas menujukan jumlah responden terbanyak usia 65 tahun - keatas sebanyak 39 responden $(54.2 \%)$, jenis kelamin perempuan 47 responden $(65.3 \%)$, pendidikan terakhir SLTA/ Sederajat 31 responden $(43.1 \%)$, pekerjaan lainnya 47 responden $(65.3 \%)$, rata - rata pendapatan perbualan 1.900.000 57 responden (79.25\%), lamanya menderita Diabetes Melitus (DM) > 5 tahun 54 responden $(75.0 \%)$, yang mengalami Hipertensi 34 responden (47\%) dan tidak merokok 67 responden (93.1\%). 
Jurnal Keperawatan, Volume 9, No. 2, Agustus 2021, (Hal. 54-62)

\section{Analisa Univariat}

Table 2. Distribusi frekuensi berdasrkan self care pada pasien DM tipe 2

\begin{tabular}{lcc}
\hline \multicolumn{1}{c}{ Self care } & Frekuensi & Presentase \\
\hline Baik & $\mathbf{3 9}$ & 54.2 \\
Kurang & $\mathbf{3 3}$ & 45.8 \\
\hline Total & 72 & 100.0 \\
\hline
\end{tabular}

Sumber : Data Primer, 2020

Table 2 menunjukkan bahwa sebagian besar pasien DM Tipe 2 mempunyai self

care yang baik yaitu 39 responden sebesar $54 . \%$.

Tabel 3. Distribusi frekuensi berdasrkan Komplikasi pada pasien DM tipe 2

\begin{tabular}{ccc}
\hline Komplikasi & Frekuensi & Presentase \\
\hline Mengalami Komplikasi & $\mathbf{4 8}$ & 66.7 \\
\hline
\end{tabular}

Sumber : Data 2020

Tabel 3 menujukkan bahwa nresponden respoden dengan presentase sebesar $66.7 \%$. yang mengalami komplikasi yaitu 48

\section{Analisa Bivariat}

Tabel 4. Destribusi hubungan self care dengan komplikasi Diabetes Melitus pada pasien Diabetes Melitus tipe 2

\begin{tabular}{cccccccc}
\hline \multicolumn{6}{c}{ Komplikasi Diabetes Melitus } & \\
\hline Self Care & $\begin{array}{c}\text { Tidak ada } \\
\text { komplikasi }\end{array}$ & $\begin{array}{c}\text { Ada } \\
\text { komplikasi }\end{array}$ & Total & p-value \\
\hline Baik & 12 & 16.7 & 27 & 37.5 & 39 & 54.2 & \\
\hline Kurang & 12 & 16.7 & 21 & 29.2 & 33 & 45.8 & 0.802 \\
& & & & & & & \\
\hline Total & $\mathbf{2 4}$ & $\mathbf{3 3 . 3}$ & $\mathbf{4 8}$ & $\mathbf{6 6 . 7}$ & $\mathbf{7 2}$ & $\mathbf{1 0 0}$ & \\
\hline
\end{tabular}

Sumber : Data 2020

Tabel 4 menunjukan bahwa Self Care baik yaitu 39 responden dimana 12 responden (16.7\%) tidak ada komplikasi dan 27 responden $(37.5 \%)$ ada komplikasi. Sedangkan untuk responden yang Self Care kurang yaitu 33 responden dimana 12 responden $(16.7 \%)$ dan 21 responen (29.2\%) ada komplikasi. Hasil uji statistik didapatkan bahwa nilai p-value $(0.802)>\alpha$ $=(0,05)$, sehingga $\mathrm{H} 0$ gagal ditolak. Kesimpulannya adalah tidak ada hubugan antara Self Care dengan komplikasi. Diabetes Melitus pada pasien Diabetes Melitus Tipe 2. 


\section{PEMBAHASAN}

\section{Analisa Univariat a. Self Care}

Berdasarkan hasil penelitian self care yang baik terdapat pada 39 responden dan self care yang buruk terdapat pada 33 responden dimana yang lebih dominan adalah self care baik. Sejalan dengan hasil penelitian yang dilakukan oleh Hartono (2019) menunjukkan bahwa sebagian besar memiliki self care baik.Tingkat kemauan dalam melakukan Self care juga berkaitan erat dengan pelaksanaan self menegemen dimana dalam penelitian yang dilakukan oleh Responden penderita DM tipe 2 yang mendapat pengetahuan baik berpeluang lebih sering untuk melaksanakan self management dengan baik dibandingkan dengan yang kurang pengetahuan (Mustarim, Nur, Azzam 2019). Pada penelitian ini presentase 54,2\% melakukan self care baik dengan hasil untuk aktivitaspengaturan pola makan/diet, olahraga, perawatan kaki, pengukuran kadar gula darah dan perawatan kaki dilakukan dengan baik oleh responden dan $45,8 \%$ responden melakukan self care kurang dengan hasil untuk aktivitas minum obat sudah baik, namun pengaturan pola makan/diet, olahraga, perawatan kaki dan monitoring gula darah masih kurang.

Berdasarkan hasil penelitian yang telah peneliti lakukan, responden yang memiliki tingkat self care yang baik cenderung lebih tinggi mengalami komplikasi dibandingkan dengan responden yang memiliki tingkat self care yang kurang. Dari 41 responden yang memiliki self care baik 29 diantaranya masih mengalami komplikasi dengan Hipertensi menjadi Komplikasi yang tertinggi dan 12 diantaranya tidak memiliki komplikasi. Sedangkan untuk responden yang memiliki self care kurang, dari 31 responden 16 responden memiliki komplikasi Hipertensi dan 11 responden yang tidak memiliki komplikasi. Perilaku merokok didapati pada responden yang memiliki self care baik dan kurang memiliki jumlah responden dan komplikasi yang sama sama yaitu masing-masing 2 responden, 1 responden memiliki komlikasi Hipertensi dan 1 responden tanpa komplikasi.

\section{b. Komplikasi}

Berdasarkan hasil penelitian yang mengalami komplikasi lebih banyak dari yang tidak mengalami komplikasi yaitu terdapat sebanyak 48 responden yang mengalami komplikasi dan yang tidak mengalami komplikasi 24 responden. Berbeda dengan Hasil penelitian yang dilakukan Hartono pada tahun 2019 dimana komplikasi diabetes mellitus pada pasien Diabetes Melitus Tipe 2 menunjukkan bahwa sebagian besar tidak mengalami komplikasi.

Pada penelitian ini dapat dilihat bahwa 47 responden memiliki komplikasi, 39 responden diantaranya memiliki riwayat $\mathrm{DM}>5$ tahun, yang paling banyak diderita oleh responden dengan jenis kelamin perempuan. Komplikasi yang paling banyak diderita oleh responden adalah hipertensi, faktor yang dapat beresiko menyebabkan hipertensi antara lain umur, dan asupan tinggi lemak (Muliani, 2016). Menurut Hasiando (2019), hipertensi merupakan penyakit yang paling sering dijumpai pada seseorang pada kategori usia lansia, pada kejadian hipertensi peningkatan usia menjadi salah satu faktor resiko yang tidak dapat dimodifikasi, hal ini disebabkan oleh kemunduran fungsi kerja pada pembuluh darah. Stres menjadi salah satu dampak psikologis yang dialami pasien diabetes, hal ini masih berkaitan dengan bertambanya usia, dimana seiring dengan bertambahnya usia akan terjadi perubahan baik itu secara fisik, psikologis, maupun intelektual yang berdampak pada rentanya tekena penyakit dan kegagalan mempertahankan hemostatis terhadap stres (Livan dkk, 2018). Peningkatan tekanan darah sering terjadi pada awal perjalan penyakit, bahkan untuk penyakit yang sudah tegak diagnosanya sangat berfluktasi sebagai dampak dari respon terhadap stres (Ramdani dkk, 2017). 
Pada penelitian ini menunjukan bahwa sebagian besar responden cenderung mengkonsumsi makanan berlemak tinggi. Mengkonsumsi lemak secara berlebih meningkatkan kadar kolesterol dalam darah, sehingga membentuk plaque yang akan menyumbat pembuluh darah dan berdampak pada kelenturan pembuluh darah yang dapat meningkatkan tekanan darah (Kartika dkk, 2016).

\section{Analisa Bivariat}

\section{a. Hubungan self care dan komplikasi}

Pada penelitian ini dimana dari data didapatkan hasil bahwa tidak ada hubungan self care dengan komplikasi deabetes melitus pada pasien diabetes melitus tipe 2 di klinik Husada Sario Manado.dimana didapatkan hasil melalui uji statistik didapatkan bahwa nilai p-value (0.802) > alfa $=(0,05)$, sehingga H0 gagal ditolak.

Hal ini disebabkan karena komplikasi yang terjadi pada penderita Diabetes Melitus tidak dapat dihindari, tetapi bisa dikendalikan dan ditundah manifestasinya, salah satunya dengan self care. Menurut Novyanda dan Hadiyani (2017), salah satu pilar dalam mengontrol dampak komplikasi pada penderita diabetes melitus adalah pengaturan pola makan/diet.

Kepatuhan penderita diabetes melitus terhadap pengaturan pola makan/diet merupakan faktor penting dalam menstabilkan kadar gula dalam darah, ketidak patuhan terhadap pengaturan pola makan/diet kan menyebabkan terjadinya komplikasi dan memperparah komplikasi. Data yang diperoleh pada pengaturan pola makan/diet responden masih tinggi mengkonsumsi asupan tinggi lemak, dimana hal ini dapat menyebabkan komplikasi ataupun memperparah komplikasi, pada data juga dapat dilihat bahwa hipertensi menjadi komplikasi yang tertinggi. Hal ini didukung oleh penelitian yang pernah dilakukan oleh Kartika pada tahun 2016 dimana mengkonsumsi lemak secara berlebih meningkatkan kadar kolesterol dalam darah yang membentuk plaque, sehingga terjadi menyumbatan pembuluh darah dan berdampak pada kelenturan pembuluh darah yang dapat meningkatkan tekanan darah. Selain itu ada beberapa faktor yang dapat mempengaruhi kurang maksimalnya perilaku.

\section{SIMPULAN}

Berdasarkan hasil analisi didapatkan tidak ada hubugan antara Self Care dengan komplikasi Diabetes Melitus pada pasien dimana didapatkan bahwa sebagian besar penderita DM Tipe 2 dengan komplikasi memiliki Self care yang baik. dan penderita DM Tipe 2 yg tidak disertai Komplikasi sebagian memiliki self care baik, sebagian memiliki self care kurang baik.

\section{DAFTAR PUSTAKA}

American Diabetes Association.(2010). Standards of Medical Care in Diabetes. Diabetes care, S11-S61

American Diabetes Association (ADA). 2012. Medical advice for people with diabetes in emergency situations Diabetes Association journal

Balitbang Kemenkes RI. (201). Riset Kesehatan Dasar; RISKESDAS. Jakarta: Balitbang.

Brunner and Suddarth.(2002). Buku Ajar Keperawatan Medika Bedah, edisi 8 Volume 2.Jakarta : EGC

Chaidir Reny,dkk (2017). Hubungan Self Care Dengan Kualitas Hidup Pasien Diabetes Melitus. Stikes Yardi Bukit Tinggi, Sumbar

Depkes RI. (2008). Diabetes Melitus Ancaman Umat Manusia di Dunia.www.depkes.go.id/indeks/.

Diabcare asia 2008 study-outcomes on control and complications of type 2 diabetic patients in indonesia, Med J Indonesia, 19.,

Ernawati. 2013. Pengaruh Efikasi Diri, Konsep Diri, Aktifitas Belajar dan Kemandirian Belajar Terhadap Hasil Belajar Matem

Hidayat, A. A. (2007). Metode Penelitian Keperawatan dan Teknik Analisa Data. Penerbit: Salemba Medika. 
International Diabetes Federation (2015). Diabetes Atlas (Seventh Edition)

International Diabetes Federation (2017). IDF Diabetes $9^{\text {th }}$ edition 2019.Diakses tanggal 10 Juni 2020di .www.idf.org

Kriska, S .(2007). Cara Mudah Mencegah Dan Mengatasi Diabetes Melitus,

Yogyakarta:Aulia Publising.

Kariadi, S. H. (2009). Diabetes?Siapa takut:Panduan Lengkap untuk Diabetesi, Keluarganya, dan Profesional Medis. Bandung: PT.Mizan Pustaka

Manaf, A. (2006). Insulin: Mekanisme Sekresi dan Aspek Metabolisme. Dalam : Aru W, dkk, editors, Ilmu Penyakit Dalam, Jilid III, Edisi keempat, Penerbit FK UI, Jakarta.

Ndraha, S. (2014).Diabetes Melitus Tipe 2 dan Tatalaksana Terkini. Medicinus, 27, 9-16.

Notoatmodjo, S. (2012). Metodologi Penelitian Kesehatan. Jakarta: Rineka Cipta

Price A. Sylvia, Loraine M Wilson. (2006) Patofisiologi: Konsep Klinis ProsesProses penyakit. Ed, 6, Vol 2. Jakarta. ECG

Padila.(2012). Buku Ajar Keperawatan Keluarga. Jogjakarta: Nuha Medika.

Pranoto.(2007). Konsep Kepatuhan. Yogyakarta: Yayasan Bina Pustaka Sarwono Prawirohardjo.

PERKENI.(2015). Konsensus Pengelolaan dan Pencegahan Diabetes Melitus Tipe 2 di Indonesia, PB.PERKENI., Jakarta.

Putri, Y. M. P. \& Wijaya, A. S. (2013). Keperawatan Medikal Bedah: Keperawatan Dewasa Teori dan contoh askep. Yokyakarta: Nuha Medika.

Rosyada, Amrina, and Indang Trihandini. (2013). Determinan Komplikasi Kronik Diabetes Melitus pada Lanjut Usia.Kesmas: National Public Health Journal 7.9 395-402.

Riset Kesehatan Dasar. (2018). Situasi dan analisa diabetes.Pusat data dan
Informasi Kementrian Kesehatan RI. Jakarta.

Riset Kesehatan Dasar (2018). Situasi dan analisis diabetes. Pusat data dan informasi kementriankesehatan RI.Jakarta

Soegondo, S., Soewondo, P., Subekti, I. (2009).Penatalaksanaan Diabetes Melitus Terpadu, Edisi kedua cetakan ketujuh, Jakarta: Balai Penerbit FKUI.

Subekti, I. (2009). Organisasi Diabetes di Indonesia. Dalam: Soegondo, S., Soewondo,P., Subekti, I., Penatalaksanaan Diabetes Melitus Terpadu. Fakultas Kedokteran Universitas Indonesia, Jakarta.

Smeltzer, S.C., \& Brenda, G. Bare. (2010). Brunner And Suddarth'sTextbook of Medical Surgical Nursing. $11^{\text {th }}$ ed. Philadelphia: Lippincott Williams \& Wilkins.

Smeltzer, Suzane C. dan Bare, Brenda G, 2002, Buku Ajar Keperawatan Medikal Bedah Brunner dan Suddarth (ED.8, Vol, 1,2), Alih bahasa oleh Agung Waluyo (dkk), EGC, Jakarta

Soeondo, P., Soegondo, S., Suastika, K., Pranoto, A., Soeatmaji, D.W., Tjokoprawiro, A . (2010). The

Soegondo (2007). Diabetes Melitus, Penatalaksanaan Terpadu, Balai Penerbitan, FKUI, Jakarta.

Sigurdardottir, A. K. (2005). Self Care in Diabetes: Modal of Factor Affecting Self-Care. Jurnal of Clinical Nursing, 301-314

Sulistria, Y. M. (2013). Tingkat Self Care Pasien Rawat Jalan Diabetes Melitus Tipe 2 di Puskesmas Kalirungkut Surabaya. Jurnal Ilmiah Mahasiswa Universitas Surabaya, 1-11

World Health Organization. (2013). Fact sheet: Diabetes mellitus. Diakses pada 2 November 2017 di http://www.who.int.

X Balitbang Kemenkes RI. (2013). Riset Kesehatan Dasar; RISKESDAS. Jakarta: Balitbang. 
Jurnal Keperawatan, Volume 9, No. 2, Agustus 2021, (Hal. 54-62)

$\mathrm{Xu}$ yin, et all.(2008). Factor Influencing

Diabetes Self-Management in Chinese people. 